\title{
ENGEVISTA
}

Página da revista: http://www.uff.br/engevista/seer/

\section{Influência do aporte térmico sobre a microestrutura em juntas soldadas de aço inoxidável AISI 304}

\author{
Camila Soares Fonseca ${ }^{1}$ \\ Ivete Peixoto Pinheiro Silva ${ }^{2}$ \\ Gabriella Soares Caldeira Brant ${ }^{3}$
}

\begin{abstract}
Resumo: A escolha adequada do aço e dos parâmetros de soldagem pode resultar num aumento da vida útil dos equipamentos. O objetivo desse trabalho é analisar a influência do aporte térmico na microestrutura de juntas soldadas do aço inoxidável AISI 304, por meio de caracterização química e metalográfica. O material analisado são chapas de aço inoxidável AISI 304, soldadas pelo processo de soldagem GMAW, na ESAB, variando apenas o aporte térmico. Após essa etapa as chapas foram cortadas, preparadas para a análise metalográfica e de microdureza. As microestruturas do metal base, zona termicamente afetada (ZTA) e zona fundida foram caracterizadas e quantificadas nesse estudo. Verificado que aumentando o aporte térmico, reduz a quantidade de ferrita na região fundida. Foi desenvolvida uma fórmula matemática que estabelece uma relação direta entre a razão de crescimento do aporte térmico com a relação de aumento da ZTA.
\end{abstract}

Palavras-chave: Aço AISI 304, GMAW, aporte térmico.

\footnotetext{
${ }^{1}$ CEFET-MG - Centro Federal de Educação Tecnológica de Minas Gerais

${ }^{2}$ CEFET-MG - Centro Federal de Educação Tecnológica de Minas Gerais

${ }^{3}$ CEFET-MG - Centro Federal de Educação Tecnológica de Minas Gerais
} 
ISSN: $1415-7314$

ISSN online: $2317-6717$

Abstract: Proper selection of steel and welding parameters can result in increased equipment life. The aim of this study is to analyze the influence of heat input on the microstructure of welded joints of AISI 304 stainless steel by chemical and metallographic characterization and develop a mathematical relationship between increased heat input and the size of the HAZ. The material analyzed are plates of AISI 304 stainless steel, welded by GMAW welding process in ESAB, only varying the heat input. After this step the plates were cut, prepared for metallographic analysis and microhardness. The microstructures of the base metal, heat affected zone (HAZ) and fusion zone were characterized and quantified in this study. Found that increasing the heat input reduces the amount of ferrite in the melt region. A mathematical formula that establishes a direct relationship between the growth rate of the thermal contribution to the rate of increase of ZTA was developed.

Keywords: AISI304, GMAW, heat input. 


\section{Introdução}

A soldagem é uma operação de fabricação de componentes ou produtos que visa obter a coalescência localizada, no qual o material é aquecido até uma temperatura adequada, com ou sem a aplicação de pressão e de metal de adição (ASM Handbook, 2004).

Quando submetidos a processos de soldagem os aços inoxidáveis podem estar sujeitos a vários problemas metalúrgicos quando expostos a determinadas faixas de temperatura. $\mathrm{Na}$ soldagem, o ciclo térmico é capaz de submeter a zona termicamente afetada (ZTA) destes materiais a estas faixas de temperatura críticas (Folkhard, 1989).

Os aços inoxidáveis austeníticos apresentam excelente resistência à corrosão e grande ductilidade, propriedades que são bem vistas para várias aplicações. Equipamentos que trabalham em ambientes de temperatura variável são uma dessas aplicações devido à estabilidade estrutural e a inexistência da temperatura de transição dúctil-frágil dos aços inoxidáveis austeníticos (Campbell, 2007).

Os aços inoxidáveis são aços de alta liga, contendo em sua composição ferro $(\mathrm{Fe})$, carbono (C) e um mínimo de 10,50\% de cromo (Cr). Outros elementos metálicos podem estar presentes nestas ligas, mas o Cr é o principal elemento que confere aos aços inoxidáveis uma elevada resistência a corrosão (Carbó, 2008).

É possível ajustar a microestrutura austenita-ferrita pela composição química na poça de fusão, através do controle da composição do metal de adição e dos gases utilizados, e pelas condições térmicas durante a soldagem(ASM Handbook, 1993).

Na soldagem GMAW (Gas Metal Arc Welding) a junção das peças ocorre através do aquecimento das mesmas com um arco elétrico localizado entre um eletrodo metálico nu e a peça (Marques, 2002). Por sua vez, quando o processo é realizado com a utilização de um gás inerte, o processo de soldagem é denominado MIG (Metal Inert Gas). Da mesma forma, quando se utiliza um gás ativo, o processo é denominado MAG (Metal Active Gas).

A energia de soldagem estabelecida durante a soldagem pode ser calculada, conforme mostrado na Equação 1 abaixo (MARQUES, 2002):

$$
\mathrm{E}=\frac{\eta \cdot \mathrm{V} \cdot \mathrm{I}}{\mathrm{v}}
$$

onde:

$\mathrm{E}=$ energia de soldagem $\mathrm{em} \mathrm{J} / \mathrm{cm}$;

$\eta=$ eficiência térmica ou rendimento do processo;

$\mathrm{V}=$ tensão no arco, em V;

$\mathrm{I}=$ corrente de soldagem, em A;

$\mathrm{v}=$ velocidade de soldagem, $\mathrm{em} \mathrm{cm} / \mathrm{s}$. 
De acordo com Andrés, Galvis e Hormaza (2011), quando se trata de solda GMAW, a zona fundida (ZF) apresenta-se com ferrita $\delta$ em duas formas "skeletal" e "lathy", além da austenita como matriz, assim mostra a figura 1 :

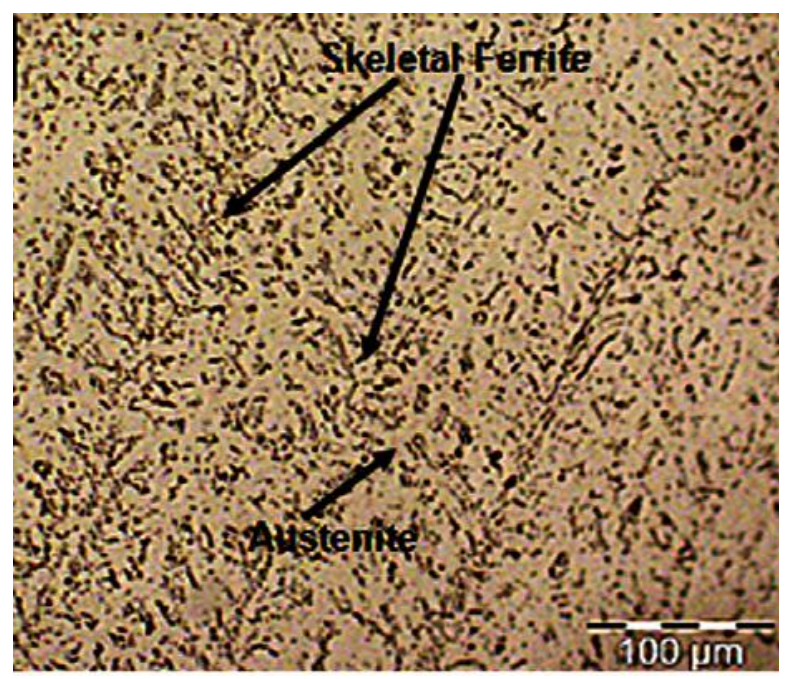

Figura 1. Zona fundida da solda GMAW.

A solidificação primária nos aços inoxidáveis austeníticos ocorre tanto como ferrita e austenita. A morfologia da ferrita é influenciada pela taxa de resfriamento e a relação $\mathrm{Cr} / \mathrm{Ni}$, assim como a quantidade de ferrita em relação a austenita.

\section{Materiais e métodos}

As chapas do aço AISI 304 foram soldadas pelo processo de soldagem GMAW, no laboratório de soldagem da ESAB. Para alcançar o aporte térmico desejado para estudo, variouse a velocidade de soldagem e os parâmetros restantes foram mantidos constantes. Foi utilizada uma tensão de 27 volts e uma corrente de 181 ampéres. Com auxílio da Eq. (1), foi calculada a velocidade de soldagem do arame sólido durante a soldagem para cada aporte térmico.

As chapas foram soldadas utilizando o arame sólido OK Autrod 308LSi, este possuía em sua composição química: $<0,03 \% \mathrm{C} ; 0,80 \% \mathrm{Si} ; 1,80 \% \mathrm{Mn} ; 20,00 \% \mathrm{Cr} ; 10,00 \% \mathrm{Ni}$; de acordo com o catalogo de Soldagem MIG/MAG Arames Sólidos ESAB. O gás de proteção utilizado foi STARGOLD FLEX da WHITE MARTINS, composição: 98\% Ar e 2\%. O processo foi realizado com um passe de solda, em posição plana. Durante a soldagem o aporte térmico foi variado em $0,5 \mathrm{~kJ} / \mathrm{mm}, 1,0 \mathrm{~kJ} / \mathrm{mm}, 1,5 \mathrm{~kJ} / \mathrm{mm}$.

Para as análises metalográficas, as amostras foram embutidas a quente com resina baquelite, lixadas manualmente com lixas de granulometria 120, 220, 320, 400 e 600 mesh, polidas com pasta de diamante de granulometria de 9, 3 e $1 \mu \mathrm{m}$ e atacadas com o reativo Kalling $\left(5 \mathrm{~g} \mathrm{CuCl}_{2}+100 \mathrm{ml} \mathrm{HCl}+100 \mathrm{ml}\right.$ Álcool Etílico. Foi realizado o ensaio de microdureza Vickers das amostras, em um microdurômetro Shimadzu HMV-2. A microdureza foi feita com replicação 
de 3 vezes. A carga utilizada foi de $0,980 \mathrm{~N}$ por 15 segundos. Foram realizadas medições a partir do centro do cordão de solda a uma distância de $0,3,0,8$ e $1,3 \mathrm{~mm}$ da superfície de topo. $\mathrm{O}$ espaçamento na zona fundida e no metal de base foi de $0,3 \mathrm{~mm}$, já na ZTA, foi de $0,1 \mathrm{~mm}$. Foi realizada a média dos 3 grupos de medições.

\section{Resultados e discussão}

A composição química do aço pode ser observada na tabela 1 abaixo.

Tabela 1. Composição química do aço AISI 304.

\begin{tabular}{l|l|l|l|l|l|l|l}
\hline$\%$ & $\mathrm{C}$ & $\mathrm{Cr}$ & $\mathrm{Ni}$ & $\mathrm{Mn}$ & $\mathrm{Si}$ & $\mathrm{P}$ & $\mathrm{S}$ \\
\hline $\begin{array}{l}\text { AISI } \\
304\end{array}$ & 0.1 & 19.0 & 8.0 & 2.0 & 1.0 & 0.1 & 0.03 \\
\hline
\end{tabular}

Ao analisar as imagens da metalografia do aço AISI304 nas fig. 2 (A), (B) e (C) é possível observar que quanto maior o aporte térmico maior será a ZTA e que no metal base (MB) verificase a presença de ferrita, como previsto pela composição química, e os grãos de austenita levemente atacados. A ferrita está alongada no sentido da laminação sofrida pela chapa. Nas fig. 2 (D), (E) E (F) é possível comparar a presença de ferrita na ZF "skeletal". Pelas imagens a concentração de ferrita diminui quando o aporte aumenta, e a dispersão é maior em aportes menores. Na fig. 2 (E), relativa ao aporte de $1,0 \mathrm{~kJ} / \mathrm{mm}$, é possível perceber além da ferrita na forma "skeletal" também a ferrita na forma "Lathy", diferente dos outros aportes. Conforme descrito por Andrés, Galvis e Hormaza em 2011, materiais soldados pelo processo GMAW podem apresentar na zona fundida com ferrita $\delta$ em duas formas "skeletal" e "lathy", além da austenita como matriz. 


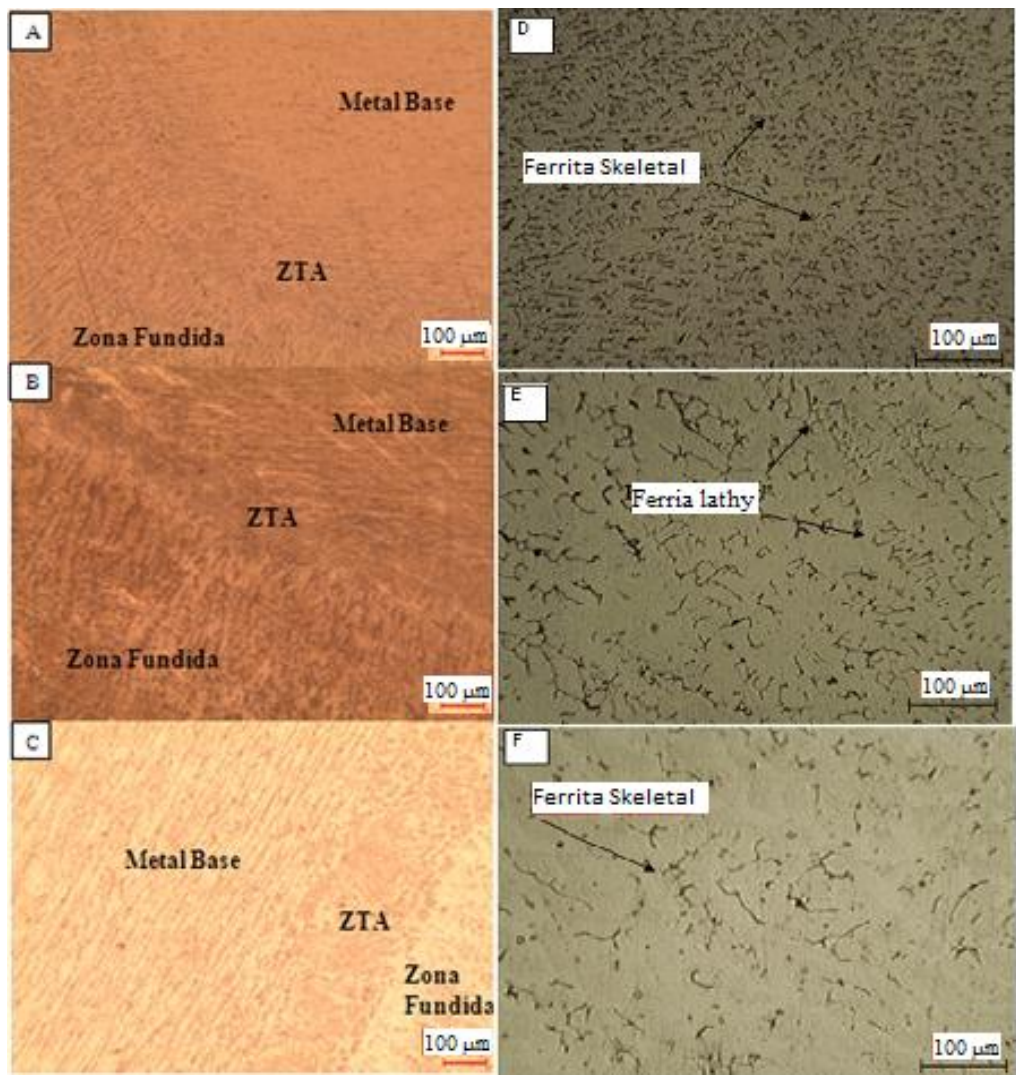

Figura 2. Micrografia do Aço AISI304 - na transição entre ZTA e MB do aporte de $0,5 \mathrm{~kJ} / \mathrm{mm}(\mathrm{A}) ; 1,0 \mathrm{~kJ} / \mathrm{mm}(\mathrm{B}) ; 1,5 \mathrm{~kJ} / \mathrm{mm}(\mathrm{C})$ e da $\mathrm{ZF}$ do aporte de $0,5 \mathrm{~kJ} / \mathrm{mm}(\mathrm{D})$; $1,0 \mathrm{~kJ} / \mathrm{mm}(\mathrm{E}) ; 1,5 \mathrm{~kJ} / \mathrm{mm}(\mathrm{F})$

Os valores medidos de tamanho da ZTA encontram-se na tabela 2 abaixo:

Tabela 2 - Tamanho médio da ZTA $(\mu \mathrm{m})$

\begin{tabular}{c|c|c|c}
\hline Aporte $(\mathrm{kJ} / \mathrm{mm})$ & 0,5 & 1,0 & 1,5 \\
\hline Tamanho da & $110 \pm$ & $154 \pm$ & $220 \pm$ \\
ZTA $(\mu \mathrm{m})$ & 10 & 10 & 10 \\
\hline
\end{tabular}

Por esse resultado pode-se estabelecer uma relação direta entre a razão de crescimento do aporte térmico com a relação de aumento da ZTA. Sendo assim, de $0,5 \mathrm{~kJ} / \mathrm{mm}$ para $1,0 \mathrm{~kJ} / \mathrm{mm}$ equivale a uma relação de $200 \%$, o aumento da ZTA, nesse caso, foi de $110 \mu \mathrm{m}$ para $154 \mu \mathrm{m}$, equivale de $140 \%$. Com esse raciocino chega-se no fator de $70 \%$ entre as razões explicadas pela equação (2) abaixo:

$$
L_{Z T A 2}=\frac{0,7 \cdot L_{Z T A 1} \cdot A p_{2}}{A p_{1}}
$$

Onde:

$L_{Z T A 2}=$ Tamanho da ZTA aporte 2

$L_{Z T A 1}=$ Tamanho da ZTA aporte1;

$A p_{2}=$ Aporte 2;

$A p_{1}=$ Aporte 1; 
O aço inoxidável inox AISI 304 sem ter sofrido nenhum tratamento térmico ou mecânico possui a dureza igual a 180HV. A dureza obtida para o material como recebido foi igual 210 $( \pm 3,5) \mathrm{HV}$. O maior valor de dureza encontrado pode ser justificado, uma vez que o material recebido é uma chapa laminada a frio, processo de conformação que resulta no encruamento do material, portanto, proporciona um aumento de dureza. Observa-se na fig. 3 o perfil de dureza para cada aporte térmico. Verifica-se que o perfil de dureza da amostra com aporte térmico de $0,5 \mathrm{~kJ} / \mathrm{mm}$ pouco variou na ZTA. Já para as amostras com aporte térmico de 1,0kJ/mm e 1,5kJ/mm a dureza apresentou um decréscimo na ZTA.

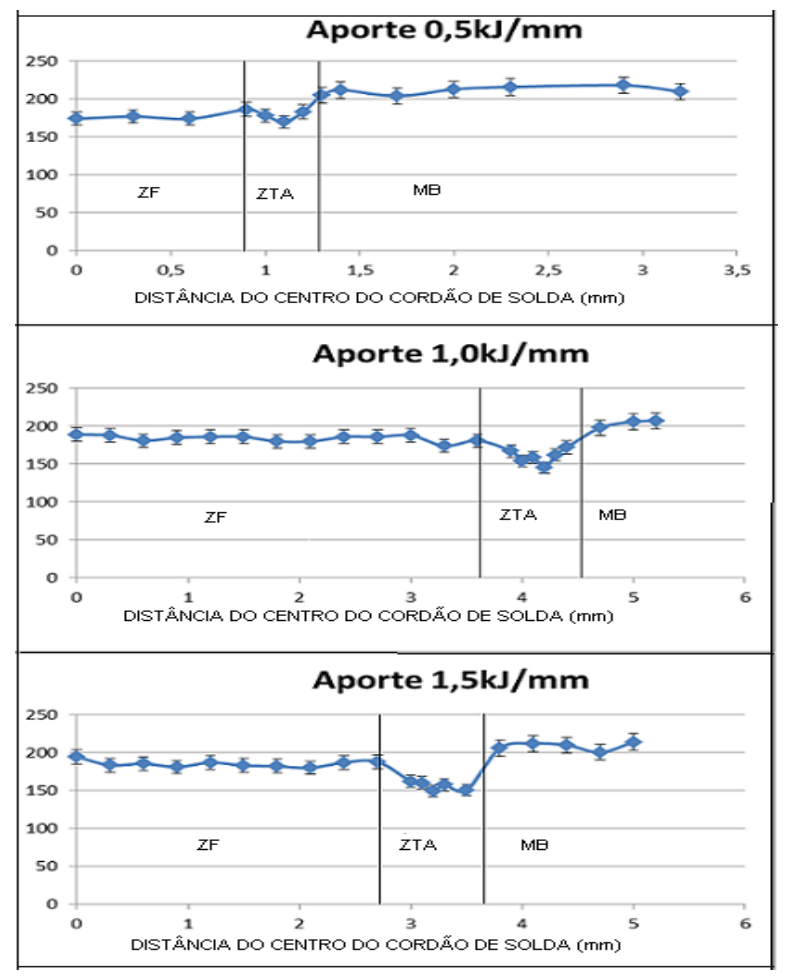

Figura 3. Perfil de dureza em função do aporte térmico do AISI 304.

\section{Conclusão}

Conclui-se que o aporte térmico influência nas características finais do cordão de solda. Quanto maior o aporte térmico durante a soldagem maior será a espessura do cordão de solda.

Os resultados demonstraram que ZTA no aço inoxidável AISI 304, durante o processo de soldagem, é pequena, resultando na pouca alteração da microestrutura nessa região.

A partir da análise das micrografias das amostras, concluiu-se que o tamanho da ZTA cresce $70 \%$ em relação ao aumento do aporte térmico, como explicado pela equação 2 .

Foi verificado que quanto maior o aporte térmico menor é a quantidade de ferrita na ZF. Aumentando o aporte térmico, e consequentemente a energia fornecida ao processo, ocorre a redução da velocidade de resfriamento, resultando no aumento da austenita. 
Por meio do perfil de dureza foi observado que o valor de dureza para todas as amostras ficaram próximas do valor do material conforme recebido. A ZF apresenta-se mais macia que o MB, possivelmente pelo teor de carbono ser menor. A ZTA apresenta menor dureza tanto em comparação a ZF, quanto ao MB. Para uma análise mais cuidadosa desse perfil de dureza, será necessária uma análise metalográfica quantitativa.

\section{Referências}

ANDRÉS R., GALVIS E., HORMAZA W. 2011. Characterization of failure modes for different welding processes of AISI/SAE 304 stainless steels. Elsevier Ltd.

ASM HANDBOOK. 2004. Metallography and microstructures. American Society for Metals ASM International.

ASM HANDBOOK. 1993. Metallography and microestructures. American Society for Metals ASM International.

BARBEDO, N. D. D. 2011.Avaliação comparativa dos processos de soldagem GMAW e FCAW utilizando aço ASTM A-36 para verificar a soldabilidade, propriedades metalúrgicas e geométricas, e resistência mecânica. Dissertação de Mestrado, Universidade Federal de Itajubá. CAMPBELL, R. D. 2007. Avoiding defects of stainless steels welds. Welding Journal, 86, 5363.

CARBÓ, H.M. 2008. Aços inoxidáveis: aplicações e especificações. Minas Gerais, Belo Horizonte.

CIRINO, L, M. 2009. Estudo dos efeitos da polaridade na soldagem com corrente contínua e alternada pelos processos TIG e MIG/MAG. Dissertação de Mestrado, Universidade Federal de Santa Catarina.

DIAS, A. O. 2009. Análise da influência dos parâmetros de pulsação na soldagem do aço inoxidável AISI 304 através do arame tubular AWS E316LT1-4. Dissertação de Mestrado, Universidade Federal de Itajubá.

FARGAS, G; ANGLADA, M; MATEO, A. 2009. Effect of the annealing temperature on the mechanical properties, formability and corrosion resistance of hot-rolled duplex stainless steel. Journal of Materials Processing and Technology, 209, 1770-1782.

FISCHER, A. 2011. Estudo da influência dos parâmetros no processo de soldagem GMAW: arco pulsado. Tese de Doutorado, Universidade Federal de Minas Gerais.

FOLKHARD E. 1989. Welding metallurgy of stainless steels. Springer-Verlag.

GNANASUNDARAM, B.R.; NATARAJAN, M. 2014. Influences of the heat input on a 2205 duplex stainless steel weld. Materials and Technology, 48, 761-763.

MARQUES, P.V. 2002. Tecnologia de soldagem. Fundação Cristiano Otoni - FCO, Minas Gerais, Belo Horizonte. 